\title{
Simple Estimation Scheme for Initial Rotor Position and Inductances for Effective MTPA-Operation in Wind-Power Systems using an IPMSM
}

\author{
Yi-Kyu Kang*, Hea-Gwang Jeong*, Kyo-Beum Lee ${ }^{\dagger}$, Dong-Choon Lee**, and Jang-Mok Kim*** \\ ${ }^{\dagger *}$ School of Electrical and Computer Eng., Ajou University, Suwon, Korea \\ ** Dept. of Electrical Eng., Yeungnam University, Gyeongbuk, Korea \\ *** School of Electrical Eng., Pusan National University, Busan, Korea
}

\begin{abstract}
This paper presents simple schemes used to estimate the initial rotor position and the $d$ - and $q$-axis inductances for effective Maximum Torque per Ampere (MTPA) operation in a wind-power system using an IPMSM (Interior Permanent Magnet Synchronous Machine). An IPMSM essentially requires an exact coordinate transformation and accurate inductance values to use a reluctance torque caused by the saliency characteristic. In the proposed high-frequency voltage testing method, there is no voltage drop caused by the resistance and the electromotive force. The initial rotor position and the inductance can be measured through an analysis of the stator current without turning the rotor. The experimental results are presented in order to illustrate the feasibility of the proposed method.
\end{abstract}

Key Words: Initial Rotor Position, IPMSM, MTPA, Synchronous Inductance

\section{INTRODUCTION}

In servo systems, industrial robots, electric vehicles and wind power systems, the demand for permanent magnet motors is increasing because of their high efficiency, wide driving range, high output torque per unit volume, etc [1][4]. Wind power facilities need to be driven for a long time after installation. An IPMSM is more suitable than a SPMSM (Surface Permanent Magnet Synchronous Machine) due to its mechanical robustness and high performance. The heat from the stator-winding decreases the possibility of demagnetizing because the permanent magnet is installed inside an iron core. Thus, an IPMSM can be driven in poor conditions [5], [6]. In addition, to the generated torque caused by the interaction between the permanent magnet and the stator winding, the additional use of the reluctance torque by the inductance difference can increase the efficiency in MTPA operation [7].

For the initial starting and for exact vector control, a permanent magnet machine requires that the initial position and rotating position of the rotor be known [8]. Generally, to get the location information of the rotor, an incremental encoder is used due to its cheap price and simple structure.

An incremental encoder determines the rotor position by using $\mathrm{A}$ and $\mathrm{B}$ pulses which are in proportion with the rotation

\footnotetext{
Manuscript received Feb. 1, 2010; revised May 26, 2010

$\dagger$ Corresponding Author: kyl@ajou.ac.kr

Tel: +81-31-219-2376, Fax: +81-31-212-9531, Ajou Univ.

* School of Electrical and Comp. Eng., Ajou Univ., Korea

** Dept. of Electrical Eng., Yeungnam Univ., Korea

*** School of Electrical Eng., Pusan National Univ., Korea
}

speed and a $\mathrm{Z}$ pulse that occurs once per revolution. However, additional sensors, such as an absolute encoder, a resolver, etc, are needed for measuring the initial rotor position.

An absolute encoder is attached during the manufacturing process and it detects the exact rotor position using the located $\mathrm{U}, \mathrm{V}$, and $\mathrm{W}$ signals which have an electrical angle difference of 60 degrees. Cumulative error does not occur through the signal transmission and it does not lose the location information of the rotor even if it is turned off.

Resolvers are comprised of a primary winding in the rotor and two secondary windings in the stator. They get the position information of the rotor through a transformed digital signal coming from the amplitude modulated signal according to the sine and cosine functions pertaining to the rotor position. The signal processing circuit used for the resolver is very complex. However, it has the advantage of a notable durability pertaining to physical shock and temperature changes, when compared to the encoder.

On the other hand, these additional sensors have various disadvantages, such as the required installation space, the increased cost of the system configuration, additional noise countermeasures caused by switching, etc. Therefore, various rotor position estimation methods, such as sensorless control, using a cheap pulse encoder, etc, have been explored and published [9]-[11].

This paper presents the MPPT and MTPA operations in a wind turbine system using an IPMSM. In order to get the initial rotor position information needed for the initial starting 


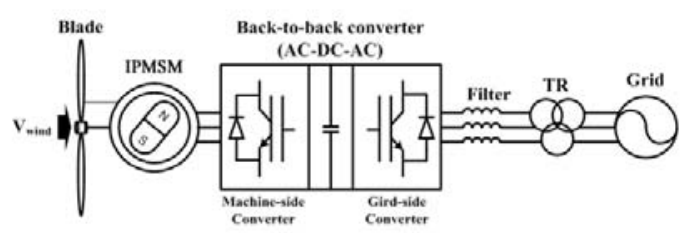

Fig. 1. The wind power generating system.

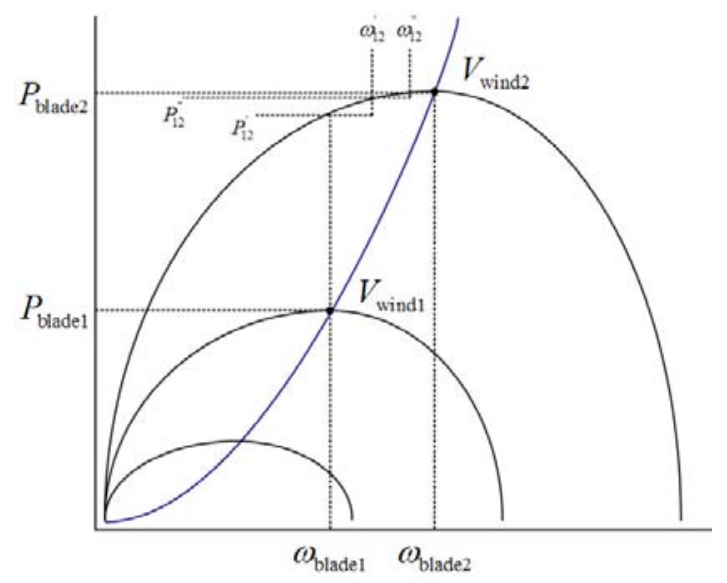

Fig. 2. The MPPT operation curve.

of a wind power system using an IPMSM, a high-frequency voltage testing method is used in this paper. The frequency of the applied voltage should be set as high as possible to make the generated torque very low. In the proposed method, the inductance difference makes an ellipse of the stator currentvector locus. The ellipse makes it possible to detect the initial rotor position through an analysis using the Least Square Method (LSM). In addition, the $d$ - $q$ inductances can be calculated from the analysis process. The proposed method has the advantage of using the updated data of the initial rotor position and inductance values each time the machine started.

The experimental results are presented in order to verify the effectiveness and feasibility of the proposed method. Also, by using a $10 \mathrm{~kW}$ wind power system simulator, the effects of the exact initial rotor position and inductance values on the MTPA performance in a wind power system using an IPMSM are analyzed.

\section{MTPA OPERATION IN A WIND POWER SYSTEM USING AN IPMSM}

\section{A. Overview of a Wind Power System}

A wind-power system using a IPMSM (Interior Permanent Magnet Synchronous Machine) is shown in Fig. 1. This system is comprised of a blade, a generator, a back-to-back converter and a filter. The mechanical torque produced from the wind is converted into electrical energy through the IPMSM. The produced electrical energy is transferred to the dc-link capacitor through the machine-side converter. The transferred dclink electrical energy is supplied to the grid through the gridside converter. The machine-side converter performs the torque control needed for Maximum Power Point Tracking (MPPT).

When the wind speed is $V_{\text {wind } 1}$, the overall system is in the normal operation $\omega_{\text {blade } 1}$ of the rotation speed and $P_{b l a d e 1}$

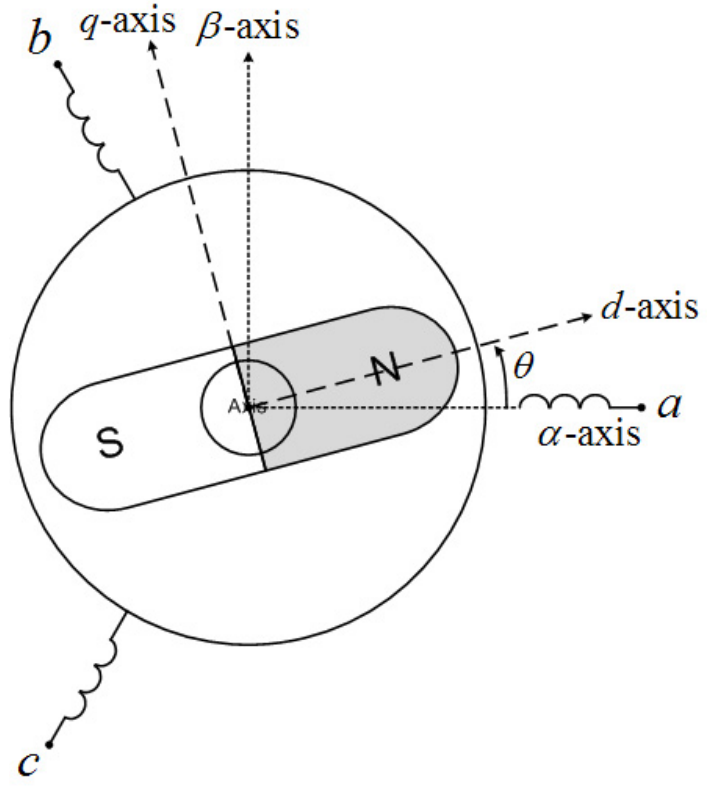

Fig. 3. The rotor cross-section of an IPMSM.

the mechanical output power. If the wind speed increases from $V_{\text {wind } 1}$ to $V_{\text {wind2 }}$, though variations in wind speed, the generator performs a torque control based on $P_{\text {blade } 1} / \omega_{\text {blade } 1}$ corresponding to $\omega_{\text {blade } 1}$ on the maximum output curve of the generator, as seen in Fig. 2. Therefore, the input torque is $P_{\text {blade } 1} / \omega_{\text {blade } 1}$ and the rotation speed is up to $\omega_{12}^{\prime}$ when the next control cycle starts. Subsequently, the torque is controlled corresponding to $\omega_{12}^{\prime}$ while the rotation speed is up to $\omega_{12}^{\prime \prime}$ as the difference between $P_{12}^{\prime} / \omega_{12}^{\prime}$ and $P_{12}^{\prime \prime} / \omega_{12}^{\prime \prime}$. Through these processes, the rotation speed can be tracked to the maximum power point.

The grid-side converter controls the dc-link voltage into a constant value. In addition, the power factor of the grid-side is set to the maximum value through the d-axis current in order to transfer the generated energy from the PMSM efficiently.

\section{B. Maximum Torque per Ampere Operation}

The rotor cross-section of an IPMSM is shown in Fig. 3. In Fig. 3, $\alpha-\beta$ and $d-q$ denote the stationary and synchronous reference frames. The $\alpha$-axis is defined in the direction of the a-phase stator winding and the $d$-axis is defined in the direction of the rotor magnetic $N$-pole.

Each coordinate transformation is defined in (1):

$$
\begin{aligned}
& {\left[\begin{array}{l}
i_{\alpha} \\
i_{\beta}
\end{array}\right]=\frac{2}{3}\left[\begin{array}{cc}
1-1 / 2 & -1 / 2 \\
0 \sqrt{3 / 2}-\sqrt{3} / 2
\end{array}\right]\left[\begin{array}{l}
i_{a} \\
i_{b} \\
i_{c}
\end{array}\right]} \\
& {\left[\begin{array}{l}
i_{d} \\
i_{q}
\end{array}\right]=\left[\begin{array}{cc}
\cos \theta & \sin \theta \\
-\sin \theta & \cos \theta
\end{array}\right]\left[\begin{array}{l}
i_{\alpha} \\
i_{\beta}
\end{array}\right] .}
\end{aligned}
$$

Since the permeability of a permanent magnet is nearly equal to air, the magnetic path of an IPMSM is different from that of a SPMSM. This characteristic causes an effect which produces an air-gap on the $d$-axis. Because the magnetroresistance on the $d$-axis is larger than on the $q$-axis, the $q$-axis inductance is larger than the $d$-axis inductance. Accordingly, 


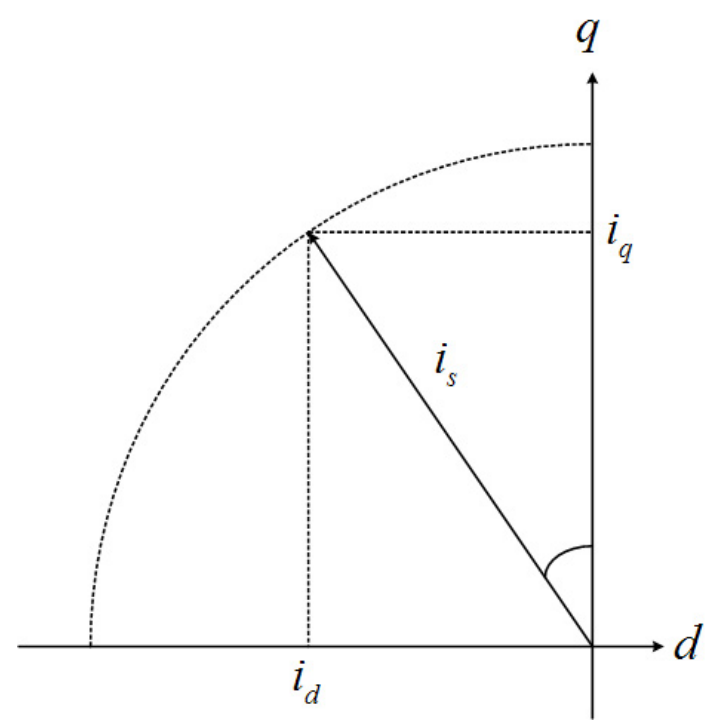

Fig. 4. The $d-$ and $q$-axis currents at the synchronous frame.

the generating torque of the IPMSM consists of the magnet torque and the reluctance torque, as follows [12]:

$$
T_{e}=\frac{3}{2} \frac{P}{2}\left[\phi_{f} i_{q}+\left(L_{d}-L_{q}\right) i_{d} i_{q}\right]
$$

where $P$ is the pole number, $\Phi_{f}$ is the stator flux, and $L_{d}$ and $L_{q}$ are the synchronous inductances on the $d$-axis and $q$-axis, respectively.

In order to generate the maximum torque, the coordinate transformation into the synchronous reference frame should be performed correctly by using (1), where the $d$ - and $q$-axis inductance values have to be exactly obtained.

In (2), the $d$-axis current $i_{d}$ uses negative values in order to add to the magnet torque. The $d$ - and $q$-axis reference currents required to generate the maximum torque need to be determined in the range of the synchronous reference frame, which is shown in Fig. 4.

MTPA operation is a method to obtain the $d$ - and $q$-axis current pair, not only for maximizing the sum of the magnet torque and the reluctance torque, but also for minimizing loss. In order to calculate the current on the maximum torque point, the torque as well as the $d$ - and $q$-axis currents are normalized as follows:

$$
\begin{aligned}
T_{e n} & =\frac{T_{e}}{T_{e b}} \\
i_{d n} & =\frac{i_{d}}{i_{b}}, i_{q n}=\frac{i_{q}}{i_{b}}
\end{aligned}
$$

where,

$$
T_{e b}=\frac{3}{2} \frac{P}{2} \phi_{f} i_{b}, i_{b}=\frac{\phi_{f}}{L_{q}-L_{d}} .
$$

Equation (2) can be simplified to (4) for the arbitrary torque in the synchronous reference frame using (3):

$$
T_{e n}=i_{q n}-i_{q n} i_{d n}
$$

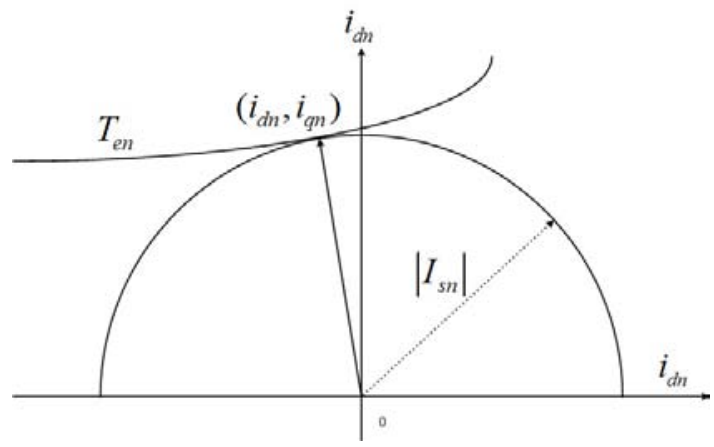

Fig. 5. The arbitrary torque curve and current circle.

As shown in Fig. 5, the locus of the intersection point $\left(i_{d n}, i_{q n}\right)$ where $T_{e n}$ and $I_{s n}$ meet is the shortest straight line from the origin to the torque curve. These $d$ - and $q$-axis currents will be the current locus to generate the maximum torque per ampere.

The equation between the normalized torque and the $d$ - and $q$-axis currents derivates a quartic equation, as shown in (5). The root of such a quartic equation can be solved as (6):

$$
\begin{aligned}
T_{e n} & =\sqrt{i_{d n}\left(i_{d n}-1\right)^{3}} \\
T_{e n} & =\frac{i_{q n}}{2}\left(1+\sqrt{1+4 i_{q n}^{2}}\right. \\
i_{d n} & =\frac{3}{4}-\frac{a_{1}}{b_{1}}-\frac{c_{1}}{d_{1}} \\
i_{q n} & =\frac{T_{e n}}{1-i_{d n}}
\end{aligned}
$$

where,

$$
\begin{aligned}
& a=T_{e n}^{2} \\
& k=-9 a+\sqrt{81 a^{2}+768 a^{3}} \\
& a_{1}=\sqrt{-73728^{1 / 3} a+3 k^{1 / 3}+96^{1 / 3} k^{2 / 3}} \\
& b_{1}=4 \sqrt{3} k^{1 / 6} \\
& c_{1}=\sqrt{3^{2 / 3} \sqrt{k}+96^{2 / 3} a a_{1}+3 k^{1 / 3} a_{1}-12^{1 / 3} k^{2 / 3} a_{1}} \\
& d_{1}=\sqrt{24} k^{1 / 6} \sqrt{a_{1}} .
\end{aligned}
$$

We can use the reference currents for the MTPA operation through the denormalization of (3).

\section{MODELING OF AN IPMSM FOR A HIGH-FREQUENCY VOLTAGE TEST}

On a stationary reference frame, the voltage equation of an IPMSM for an analysis of the stator current is given as follows:

$$
\begin{aligned}
& {\left[\begin{array}{l}
v_{\alpha} \\
v_{\beta}
\end{array}\right]=R_{s}\left[\begin{array}{l}
i_{\alpha} \\
i_{\beta}
\end{array}\right]+p\left[\begin{array}{cc}
a+b \cos 2 \theta & -b \sin 2 \theta \\
-b \sin 2 \theta & a-b \cos 2 \theta
\end{array}\right]\left[\begin{array}{l}
i_{\alpha} \\
i_{\beta}
\end{array}\right]} \\
& +\phi_{f}\left[\begin{array}{c}
\cos \theta \\
\sin \theta
\end{array}\right]
\end{aligned}
$$

where,

$$
a=\frac{L_{q}+L_{d}}{2}, b=\frac{L_{q}+L_{d}}{2} .
$$


while $R_{s}$ is the stator resistance, $p$ is the differential operator, and $\theta$ is the rotor position.

According to (1), the voltage equation on a synchronous reference frame is given as follows:

$$
\left[\begin{array}{l}
v_{d} \\
v_{q}
\end{array}\right]=R_{s}\left[\begin{array}{cc}
R_{s}+p L_{d}-\omega_{r} L_{q} \\
\omega_{r} L_{d} & R_{s}+p L q
\end{array}\right]\left[\begin{array}{c}
i_{d} \\
i_{q}
\end{array}\right]+\left[\begin{array}{c}
0 \\
\omega_{r} \phi_{f}
\end{array}\right]
$$

When high-frequency voltages are applied to a permanent magnet machine, the electromotive force is nonexistent due to the rotor inertia, so $\omega_{r}$ is ignored, as follows [13]:

$$
\left[\begin{array}{l}
v_{d} \\
v_{q}
\end{array}\right]=\left[\begin{array}{cc}
R_{s}+p L_{d} & 0 \\
0 & R_{s}+p L_{q}
\end{array}\right]\left[\begin{array}{l}
i_{d} \\
i_{q}
\end{array}\right] .
$$

The $d$ - and $q$-axis currents are derived when high-frequency voltage is applied to the motor. The applied high-frequency voltage is given as:

$$
\begin{aligned}
& {\left[\begin{array}{l}
v_{d i} \\
v_{q i}
\end{array}\right]=v_{\text {mag }}\left[\begin{array}{l}
\cos \left(\omega_{i} t\right) \\
\sin \left(\omega_{i} t\right)
\end{array}\right]} \\
& \left(\frac{v_{d i}}{v_{m a g}}\right)^{2}+\left(\frac{v_{q i}}{v_{m a g}}\right)^{2}=\cos ^{2}\left(\omega_{i} t\right)+\sin ^{2}\left(\omega_{i} t\right)=1 .
\end{aligned}
$$

Substituting (10) into (9) and solving it with respect to the $d$ - and $q$-axis currents is given as follows:

$$
\begin{aligned}
& i_{d i}=\frac{V_{m a g}}{\sqrt{R_{s}^{2}+\left(\omega_{i} L_{d}\right)^{2}}} \cos \left(\omega_{i} t-\delta_{d}\right), \delta_{d}=\tan ^{-1}\left(\frac{\omega_{i} L_{d}}{R_{s}}\right) \\
& i_{q i}=\frac{V_{m a g}}{\sqrt{R_{s}^{2}+\left(\omega_{i} L_{d}\right)^{2}}} \sin \left(\omega_{i} t-\delta_{q}\right), \delta_{q}=\tan ^{-1}\left(\frac{\omega_{i} L_{q}}{R_{s}}\right)(1
\end{aligned}
$$

where $V_{m a g}$ is the magnitude of the high-frequency voltage and $\omega_{i}$ is the input high-angle frequency.

Most of the applied voltage appears on the voltage drop caused by the stator inductance. This voltage is large enough that we can ignore the voltage drop caused by the stator resistance. Thus, (11) can be simplified by ignoring $R_{s}$ :

$$
\begin{aligned}
i_{d i} & =\frac{V_{m a g}}{\omega_{i}} \frac{1}{L_{d}} \sin \left(\omega_{i} t\right) \\
i_{q i} & =\frac{V_{m a g}}{\omega_{i}} \frac{1}{L_{q}} \cos \left(\omega_{i} t\right) .
\end{aligned}
$$

Through (12), the relationship between the $d$-axis current and the $q$-axis current is the ellipse that follows. For the IPMSM, $L_{d}<L_{q}$, thus the $i_{d}$ becomes larger than the $i_{q}$. The magnetic $N$-pole (major axis) indicates the $d$-axis on the synchronous reference frame.

$$
\left(\frac{i_{d}}{\left(V_{\text {mag }} / \omega_{i} L_{d}\right)}\right)^{2}+\left(\frac{i_{q}}{\left(V_{\text {mag }} / \omega_{i} L_{q}\right)}\right)^{2}=1 .
$$

Fig. 6 shows a schematic drawing of the current ellipse in a practical case when the initial rotor position at $\theta=0$. Compared with the initial rotor position of true, the current ellipse has an error of $\theta_{e}$ in the experimental result.

The displacement angle $\theta_{e}$ is caused by the armature impedance, such as the variation of $R_{s}$, due to external

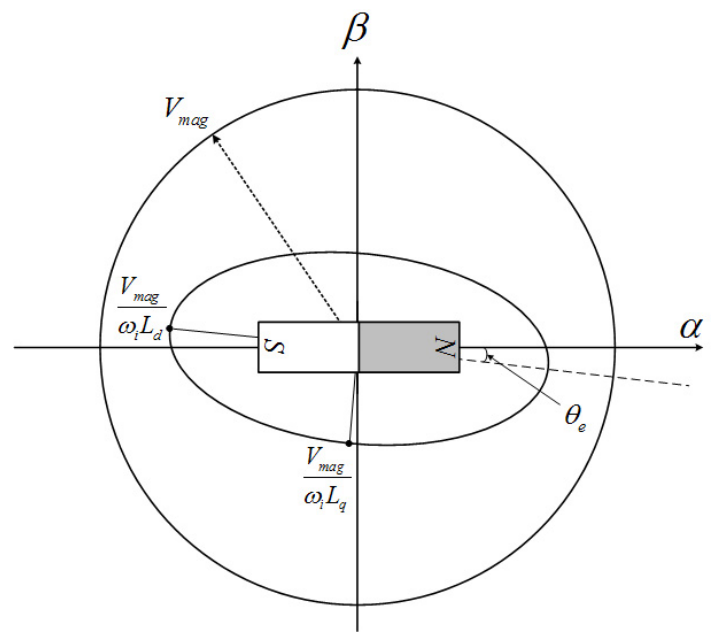

Fig. 6. The voltage locus and current locus at $\theta=0$.

cable resistance or a temperature change. These variations of $R_{s}$ cause a detrimental estimation error of the initial rotor position, which could possibly result in an unexpected rotation. Thus, the proposed estimation method considers the angle of $\theta_{e}$. The angle $\theta_{e}$ can be measured as the displacement angle in the case of $\theta$.

As seen in the above equations, if the magnetic $N$-pole does not set to zero electrical degrees, the major axis of the current ellipse is the same as the magnetic location. Despite the transition of the major axis, the current locus on the stationary reference frame always keeps the same ellipse through (12). The changed rotation angle of the ellipse can be determined with the stator current function of the rotor position. From (13), the inductance value is measured by the major and minor axes of the ellipse. Consequently, the ellipse gives information on the initial rotor position as well as the $d$ - and $q$-axis inductances.

\section{LEAST SQUARE METHOD FOR MEASURING THE INITIAL ROTOR POSITION AND INDUCTANCE}

When the ellipse rotates around the origin, arbitrary $(x, y)$ values on the rectangular coordinates are transformed as follows:

$$
\left[\begin{array}{l}
x^{\prime} \\
y^{\prime}
\end{array}\right]=\left[\begin{array}{cc}
\cos \theta_{\gamma} & \sin \theta_{\gamma} \\
-\sin \theta_{\gamma} \cos \theta_{\gamma}
\end{array}\right]\left[\begin{array}{l}
x \\
y
\end{array}\right]
$$

By substituting (14) into the normal form of an ellipse and solving it, the rotational transformed ellipse equation (15) is obtained:

$$
\begin{aligned}
& \left(\frac{\cos ^{2} \theta_{\gamma}}{a^{2}}+\frac{\sin ^{2} \theta_{\gamma}}{b^{2}}\right) x^{\prime 2} \\
& +\left(\frac{2 \cos ^{2} \theta_{\gamma} \sin \theta_{\gamma}}{b^{2}}+\frac{2 \cos \theta_{\gamma} \sin \theta_{\gamma}}{a^{2}} x^{\prime} y^{\prime}\right) x^{\prime 2} \\
& +\left(\frac{\sin ^{2} \theta_{\gamma}}{a^{2}}+\frac{\cos ^{2} \theta_{\gamma}}{b^{2}}\right) y^{\prime 2}=1
\end{aligned}
$$

where $a$ is the length of the major axis and $b$ is the length of the minor axis on the ellipse. Comparing (15) with (16) the 
rotational transformed normal form of an ellipse, $a, b$ and $\theta_{\gamma}$ can be obtained from $A, B$ and $C$ by using the LSM method:

$$
A x^{2}+B x y+C y^{2}=1 .
$$

Using the LSM, (16) transforms to (14) after substituting $i_{\alpha}$ with $x$ and $i_{\beta}$ with $y$ :

$$
x y=\frac{1}{B}-\left(\frac{A}{B}\right) x^{2}-\left(\frac{C}{B}\right) y^{2} .
$$

The variables in (17) are replaced by (18). Equation (19) is determined by (17) and (18).

$$
\begin{aligned}
& R_{1}=\frac{1}{B}, R_{2}=-\frac{A}{B}, R_{3}=-\frac{C}{B} \\
& M_{1}=1, M_{2}=x^{2}, M_{3}=y^{2}, M_{4}=x y \\
& \Sigma M_{4} M_{1}=R_{1} \Sigma M_{1}^{2}+R_{2} \Sigma M_{1} M_{2}+R_{3} \Sigma M_{1} M_{3} \\
& \Sigma M_{4} M_{2}=R_{1} \Sigma M_{1} M_{2}+R_{2} \Sigma M_{2} M^{2}+R_{3} \Sigma M_{2} M_{3} \\
& \Sigma M_{4} M_{3}=R_{1} \Sigma M_{1} M_{3}+R_{2} \Sigma M_{2} M_{3}+R_{3} \Sigma M_{3} M^{2} .
\end{aligned}
$$

The replaced $M_{1}, M_{2}, M_{3}$ and $M_{4}$, as row vectors, can be used by the LSM after accumulating as much data as the sampling frequency. Thus a large sampling frequency is needed to draw an accurate ellipse. However, too large a sampling frequency makes the CPU processing speed slow. Therefore, the sampling frequency needs to be selected properly. $A, B$ and $C$ can be solved from $R_{1}, R_{2}$ and $R_{3}$ through (19).

Comparing $A, B$ and $C$ with (15), the rotation angle of the ellipse and length of the major-minor axes can be obtained as follows:

$$
\begin{aligned}
& \theta_{\gamma}=\tan ^{-1}\left(\frac{B X}{X^{2}-A X+C X}\right) \\
& a=\sqrt{2} \sqrt{\frac{A+C+X}{4 C A-B^{2}}} \\
& b=\sqrt{2} \sqrt{\frac{A+C-X}{4 C A-B^{2}}}
\end{aligned}
$$

where,

$$
X=\sqrt{-2 C A+B^{2}+A^{2}+C^{2}} .
$$

The $d$ - and $q$-axis inductances can be obtained from (13) as follows:

$$
L_{d}=\frac{V_{m a g}}{\omega_{i} \cdot a}, L_{q}=\frac{V_{m a g}}{\omega_{i} \cdot b} .
$$

Fig.7 shows an ellipse which is drawn by using 10 points to verify the performance of the proposed LSM. Fig. 8 is an ellipse which is drawn by using 9 accurate points and 1 disturbance point. In the case of Fig. 7, the LSM draws an accurate ellipse. However, if the points contain a disturbance point, the LSM draws an inaccurate ellipse. The disturbance point distorts both the rotation axis and the length of the majorminor axes.

One advantage of the LSM is that it can be obtained easily by using a Digital Signal Processor (DSP). When extracting an ellipse through the stator current, the LSM is affected by disturbances caused by noise.

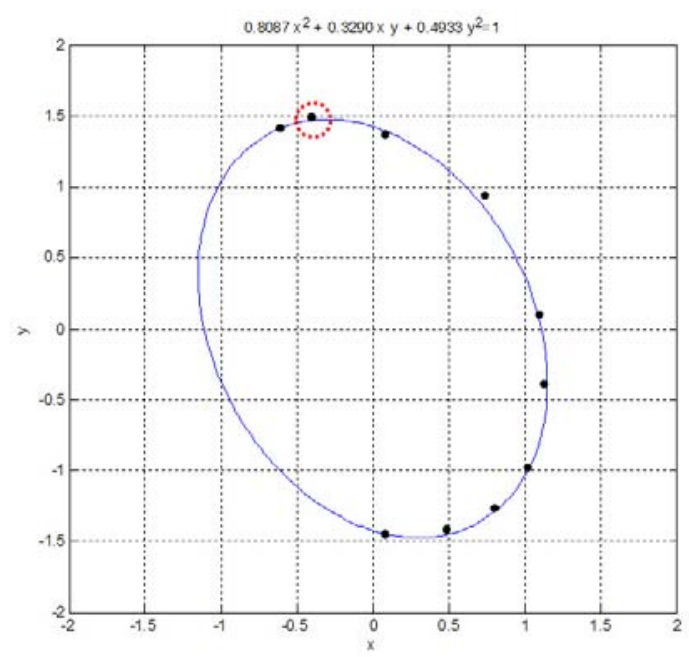

Fig. 7. The accurate ellipse by using 10 points.

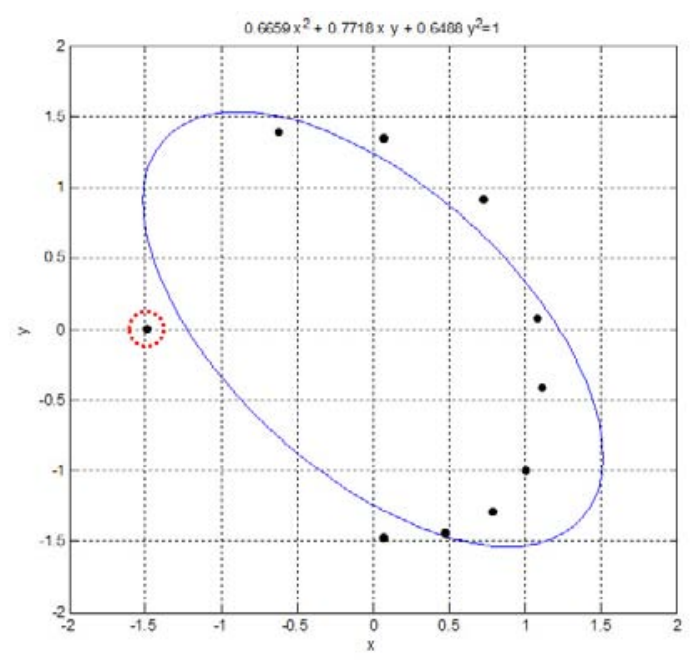

Fig. 8. The transformed ellipse caused by a noise-point.

\section{EXPERIMENTS}

In order to confirm the validity of the proposed method, experiments were carried out. In Table I and Fig. 9, the experimental conditions, the schematic diagram, and actual pictures of the experimental setup are shown.

The machine and generator (MG) set for the wind power simulation consists of a $15 \mathrm{~kW}, 380 \mathrm{~V}, 1770 \mathrm{rpm}, 4$-pole induction machine and a $11 \mathrm{~kW}$, 6-pole IPMSM. The switching frequency of the power converters is $2 \mathrm{kHz}$. Three parallel back-to-back converters (intelligent power modules - IPM) are used in order to reduce the rated power capacity of the switches. The grid connection filters are designed as deltaconnected LCL-filters in order to reduce the current harmonics.

Fig. 10 shows a current ellipse on the stationary reference frame at each electrical degree obtained by the proposed method. Since the $q$-axis inductance is larger than the $d$ axis inductance in the IPMSM, the amplitude of the $q$-axis current is smaller than the $d$-axis current on the synchronous reference frame. The initial rotor position and the $d$ - and $q$ axis inductances can be calculated by the rotation degree while the major-minor axes of the ellipse are obtained by the data 


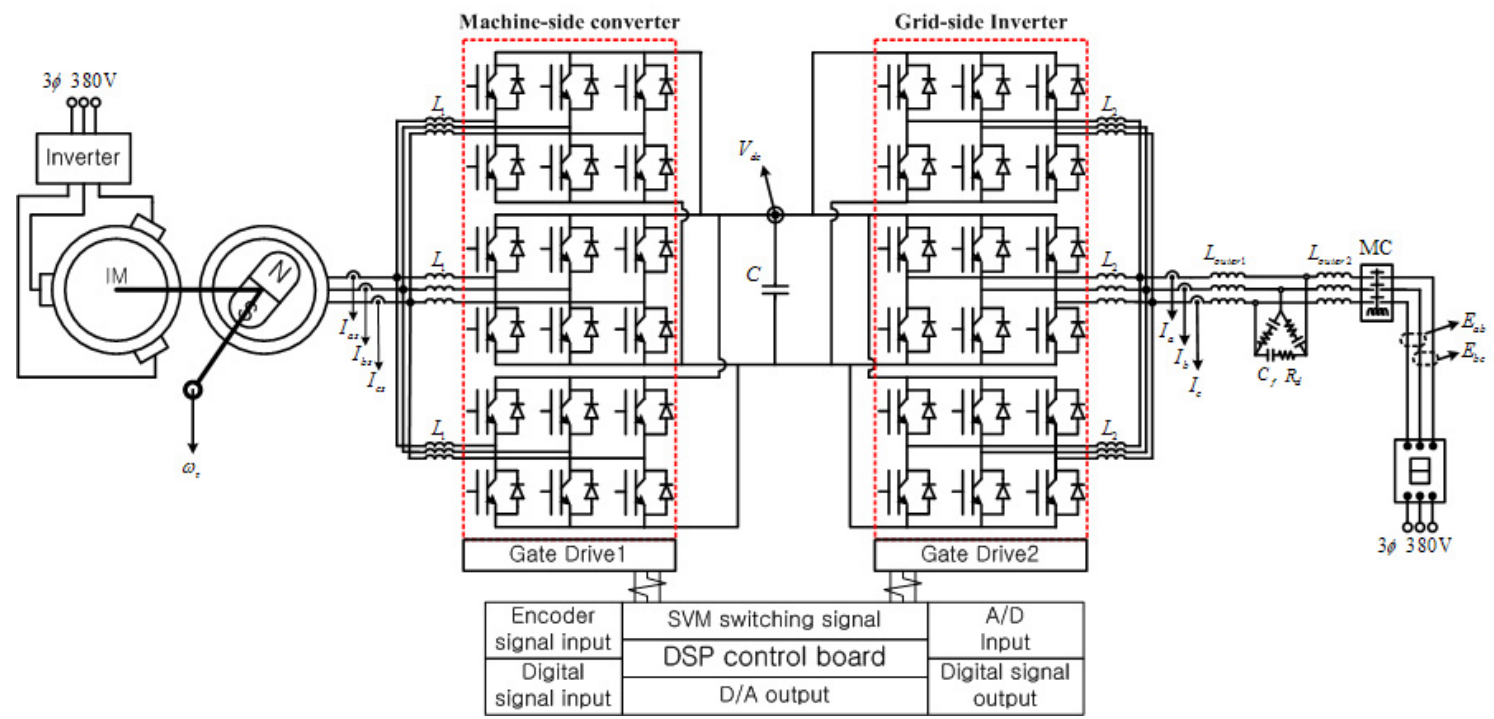

(a) The schematic diagram of the experimental setup.

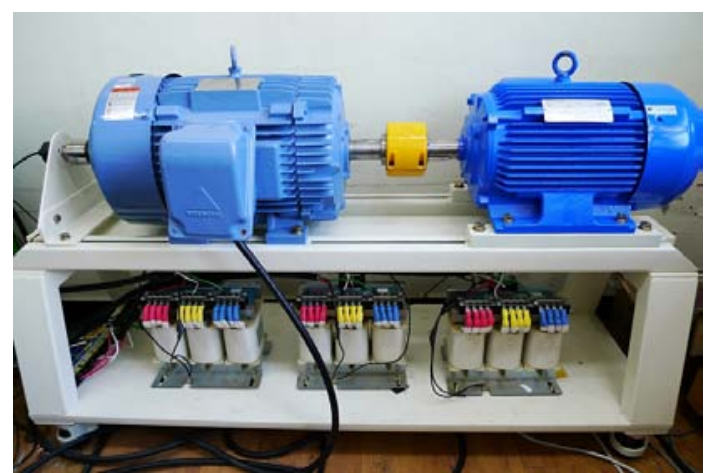

(b) The MG-set.

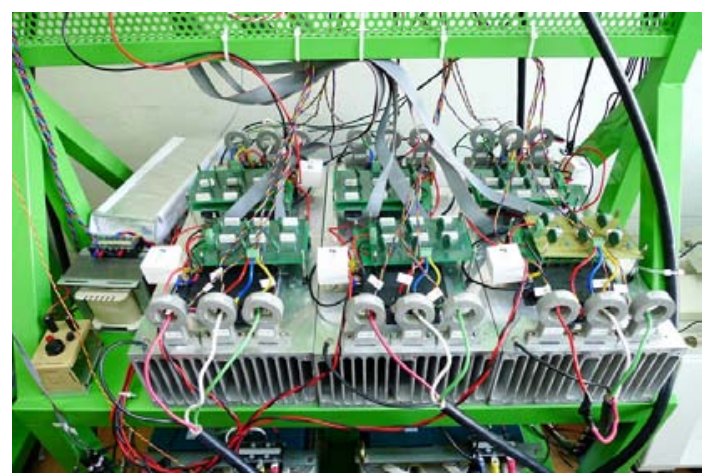

(c) The power converter.

Fig. 9. The structure of the experimental setup.
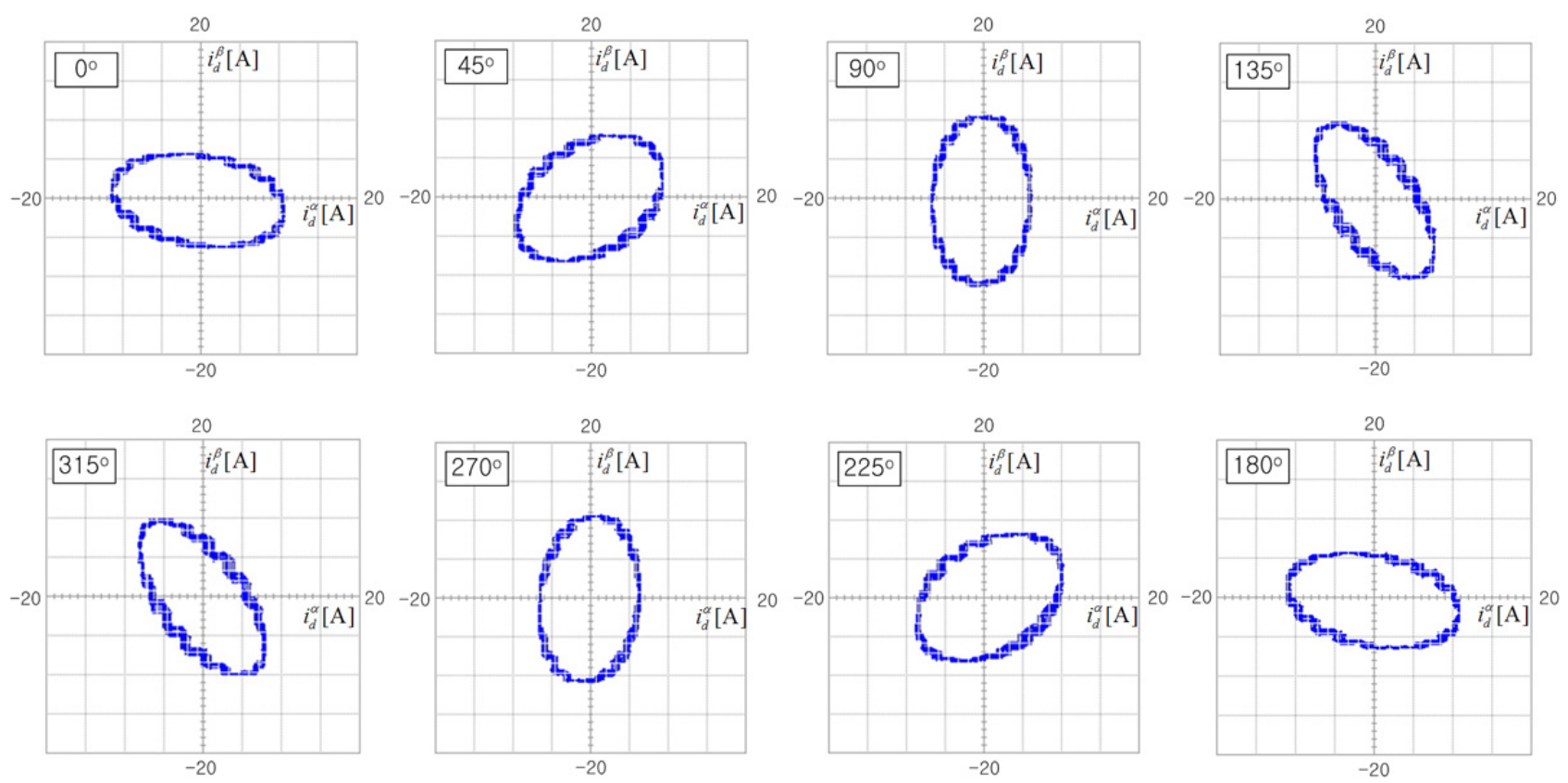

Fig. 10. Current Ellipses. 


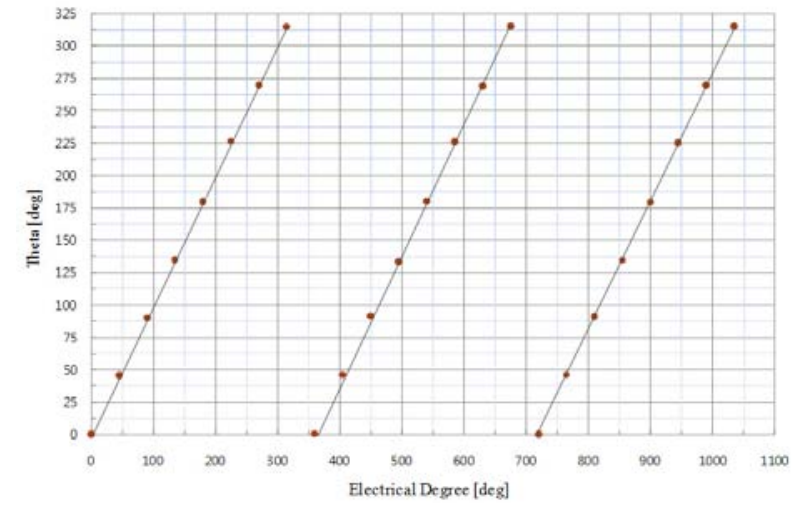

(a) Case $1\left(V_{d c}=540 \mathrm{~V}\right.$, duty ratio $\left.=0.1\right)$.

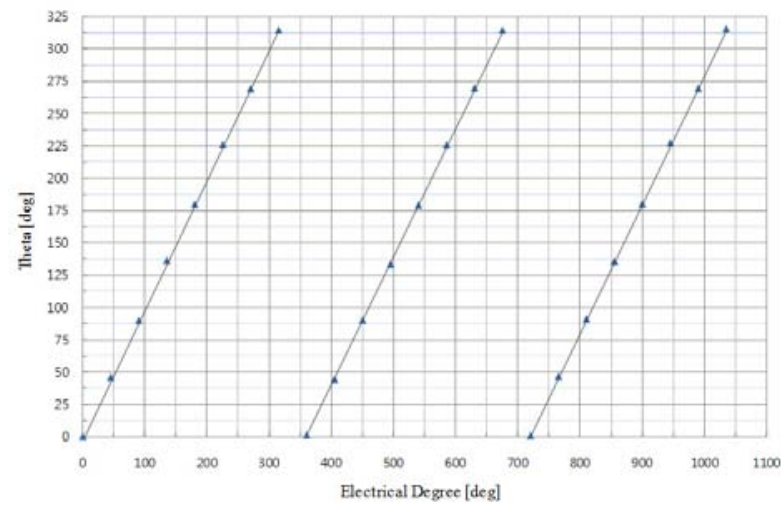

(b) Case $2\left(V_{d c}=540 \mathrm{~V}\right.$, duty ratio $\left.=0.05\right)$.

Fig. 11. The estimated results of the initial rotor position.

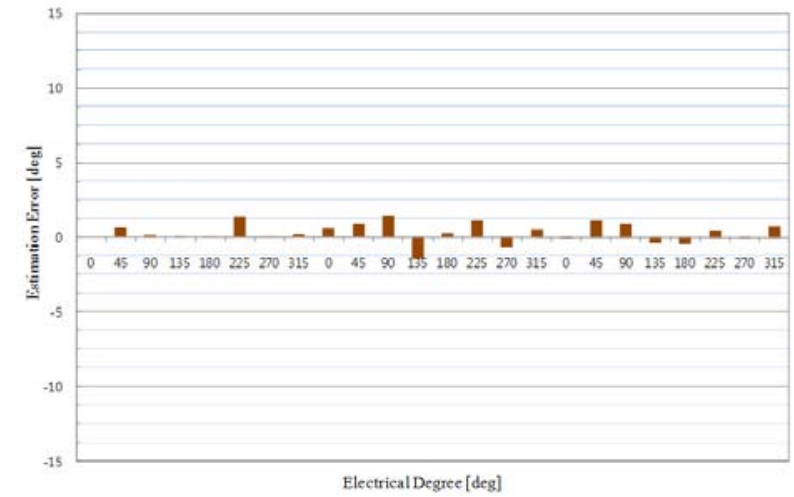

(a) Case1 $\left(V_{d c}=540 \mathrm{~V}\right.$, duty ratio=0.1).

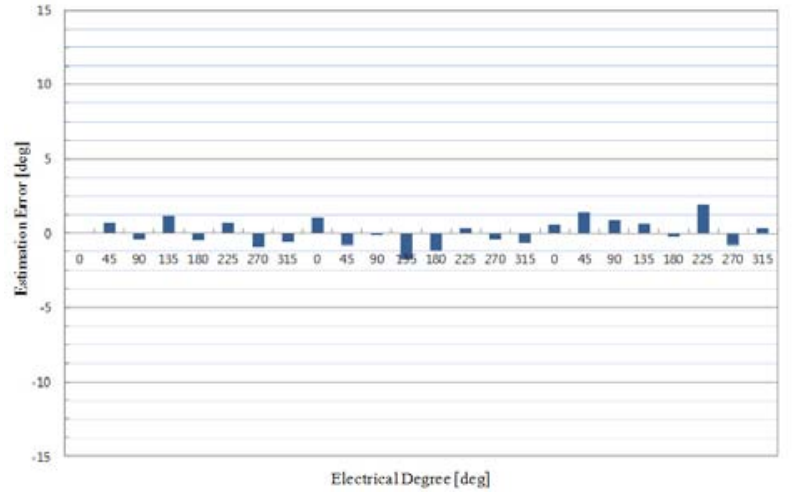

(b) Case2 $\left(V_{d c}=540 \mathrm{~V}\right.$, duty ratio $\left.=0.05\right)$.

Fig. 12. The estimation error.

TABLE I

THE SYSTEM SPECIFICATIONS

\begin{tabular}{|c|c|}
\hline \multicolumn{2}{|c|}{ Generator side } \\
\hline Rated power & $11 \mathrm{~kW}$ \\
\hline Rated torque & $72.4 \mathrm{~N} \cdot \mathrm{m}$ \\
\hline Rated speed & $1450 \mathrm{rpm}$ \\
\hline Stator resistance & $0.099 \Omega$ \\
\hline Gear Ratio & 4.4394 \\
\hline \multicolumn{2}{|l|}{ Grid side } \\
\hline DC-link voltage & $600 \mathrm{~V}$ \\
\hline DC-link capacitance & $2200 \mathrm{uF}$ \\
\hline Line-to-line voltage & $380 \mathrm{~V}$ \\
\hline Inner inductance (LCL) & $4 \mathrm{mH}$ \\
\hline Capacitance(LCL) & $7.5 \mathrm{uF}$ \\
\hline Inner inductance(LCL) & $3 \mathrm{mH}$ \\
\hline Damping resistance & $9 \Omega$ \\
\hline
\end{tabular}

of the stator current through the LSM.

Fig. 11 shows the estimated rotor positions found by using the LSM. These results show that the electrical angle rotates from 0- to 1035-degrees, which coincides with the 360degrees of mechanical angles, because there are six poles in an IPMSM. Fig. 12 shows the error of the estimated rotor position between the real and the estimated values. It can be observed from these results that the real rotor position almost corresponds to the estimated value.

Table II shows the estimated $d$ - and $q$-axis inductances of the IPMSM. To improve accuracy, the experiments are performed
20 times and the estimated inductance data is chosen from the mean value of the repeatedly performed experimental results.

TABLE II

THE ESTIMATION DATA OF THE D-Q INDUCTANCES

\begin{tabular}{|c|c|c|c|c|c|}
\hline & $L_{d}$ & $L_{q}$ & & $L_{d}$ & $L_{q}$ \\
\hline 1 & 0.003302 & 0.006507 & 11 & 0.003368 & 0.006571 \\
\hline 2 & 0.003333 & 0.006407 & 12 & 0.003451 & 0.006377 \\
\hline 3 & 0.003301 & 0.00669 & 13 & 0.003315 & 0.00667 \\
\hline 4 & 0.003352 & 0.006382 & 14 & 0.003406 & 0.006304 \\
\hline 5 & 0.003326 & 0.0064 & 15 & 0.00336 & 0.006596 \\
\hline 6 & 0.003284 & 0.006437 & 16 & 0.003379 & 0.006512 \\
\hline 7 & 0.003322 & 0.006545 & 17 & 0.003327 & 0.006468 \\
\hline 8 & 0.003275 & 0.006554 & 18 & 0.003487 & 0.00656 \\
\hline 9 & 0.00336 & 0.006622 & 19 & 0.003398 & 0.006437 \\
\hline 10 & 0.003387 & 0.006535 & 20 & 0.003437 & 0.006568 \\
\hline \multicolumn{4}{|c|}{ Average } & 0.003359 & 0.006507 \\
\hline
\end{tabular}

The accuracy of the estimated initial rotor position and the $d$ - and $q$-axis inductances are validated by using them in a wind power simulator drive. Fig. 13 shows the MTPA characteristics in a wind power system using the estimated initial rotor position and inductances obtained by the proposed methods. The corresponding reference torque is transferred to the IPMSM under the modeling of a wind velocity at $9 \mathrm{~m} / \mathrm{s}$. The total current, which makes the reference torque, is decreased by using the generated reluctance torque [14]. 


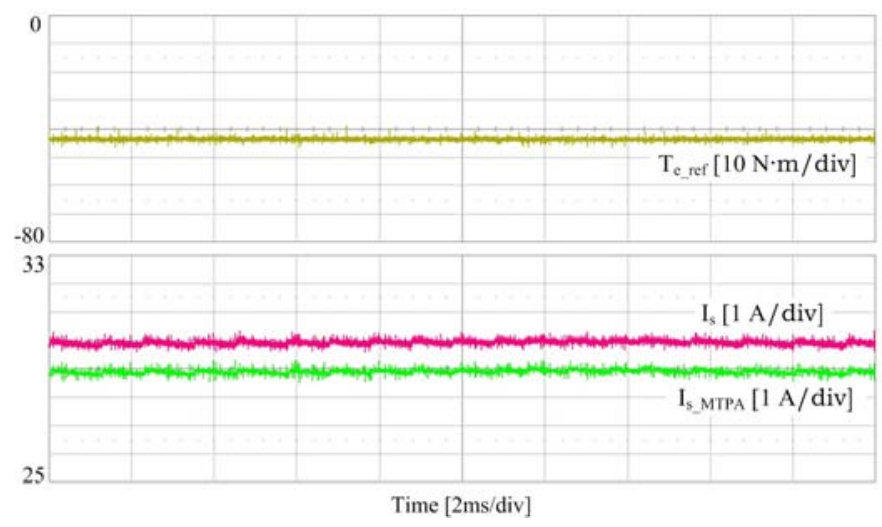

(a)

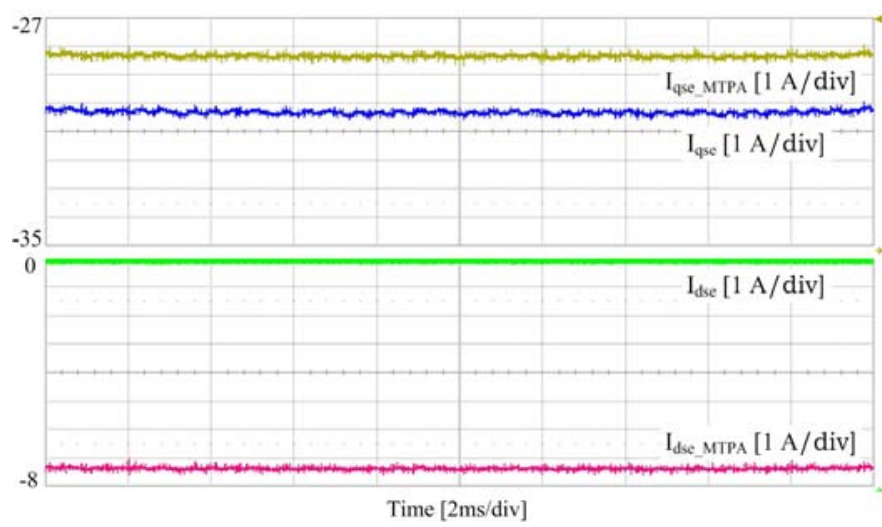

(b)

Fig. 13. The MTPA operation.

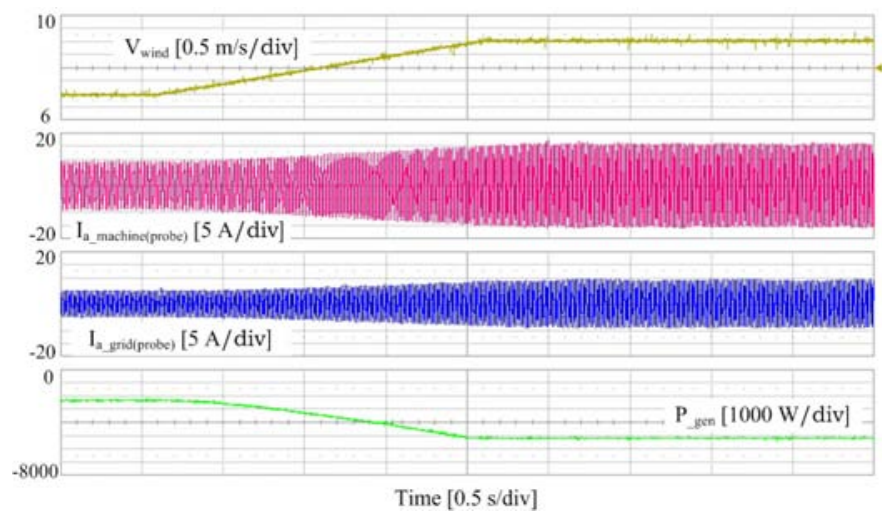

Fig. 14. Experimental result of a complete generation system.

The MTPA operation with a reduced $q$-axis current and the generated minus $d$-axis current is confirmed in Fig. 13(b).

Fig. 14 shows the dynamic characteristics of a complete generation system when the modeled wind velocity changes from $7 \mathrm{~m} / \mathrm{s}$ to $9 \mathrm{~m} / \mathrm{s}$ under the conditions of the MTPA and the MPPT operations. Both the machine- and grid-side currents increase along with the reference torque [15]. It can be seen from these experimental results that the MPTA and the MPPT operate well using the estimated values obtained by the proposed methods.

\section{CONCLUSIONS}

This paper proposes a simple method used to estimate an initial rotor position as well as the $d$ - and $q$-axis inductances of an IPMSM used in wind turbines without turning the rotor. The validity of the proposed method, using high-frequency voltage tests and the least square method, was demonstrated by experimental results. Using a $10 \mathrm{~kW}$ wind power simulator, effective MTPA operation and the dynamic characteristics of MPPT operation were confirmed using the estimated initial rotor position and $d$ - and $q$-axis inductances.

\section{REFERENCES}

[1] W. Qiao, L. Qu, and R. G. Harley, "Control of IPM synchronous generator for maximum wind power generation considering magnetic saturation," IEEE Trans. Industry Applications, Vol. 45, No. 3, pp. 10951105, May/Jun. 2009.

[2] M. Chinchilla, S. Arnaltes, and J. C. Burgos, "Control of permanentmagnet generators applied to variable-speed wind-energy systems connected to the grid," IEEE Trans. Energy Conversion, Vol. 21, No. 1, pp. 130-135, Mar. 2006.

[3] S. Brabic, N. Celanovic, and V. A. Katic, "Permanent magnet synchronous generator for wind turbine application," IEEE Trans. Power Electronics, Vol. 13, No. 3, pp. 1136-1142, May 2008.

[4] S. T. Jou, S. B. Lee, Y. B. Park, and K. B. Lee, "Direct power control of a DFIG in wind turbines to improve dynamic responses," Journal of Power Electronics, Vol. 9, No. 5, pp. 781-790, Sep. 2009.

[5] Y. Chen, P. Pillay, and A. Khan, "PM wind generator topologies," IEEE Trans. Industry Applications, Vol. 41, No. 6, pp. 1619-1626, Nov./Dec. 2005.

[6] R. Dutta and M. F. Rahman, "Design and analysis of an interior permanent magnet (IPM) machine with very wide constant power operation range," IEEE Trans. Energy conversion, Vol. 23, No. 1, pp. 25-33, Mar. 2008.

[7] C. T Pan and S. M. Sue, "A linear maximum torque per ampere control for IPMSM drives over full-speed range," IEEE Trans. Energy Conversion, Vol. 21, No. 2, pp. 359-366, Jun. 2005.

[8] A. Piippo, M. Hinkkanen, and J. Luomi, "Adaptation of motor parameters in sensorless PMSM drives," IEEE Trans. Industry Applications, Vol. 45, No. 1, pp. 203-212, Jan./Feb. 2009.

[9] S. Morimoto, M. Sanada, and Y. Takeda, "Mechanical sensorless drives of IPMSM with online parameter identification," IEEE Trans. Industry Applications, Vol. 42, No. 5, pp. 1241-1248, Sep./Oct. 2006.

[10] N. Bianchi, S. Bolognani, J. H. Jang, and S. K. Sul, "Comparison of PM motor structures and sensorless control techniques for zero-speed rotor position detection," IEEE Trans. Power Electronics, Vol. 22, No. 6, pp. 2466-2475, Nov. 2007.

[11] Y. S. Jeong, R. D. Lorenz, Jahns. T. M, and S. K. Sul, "Initial rotor position estimation of an interior permanent-magnet synchronous machine using carrier-frequency injection methods," IEEE Trans. Industry Applications, Vol. 41, No. 1, pp. 38-45, Jan./Feb. 2005.

[12] J. M. Kim and S. K. Sul, "Speed control of interior permanent magnet synchronous motor drive for the flux weakening operation," IEEE Trans. Industry Applications, vol. 33, No. 1, pp. 43-48, Jan./Feb. 1997.

[13] S. Kondo, A. Takahashi, and T. Nishida, "Armature current locus-based estimation method of rotor position of permanent magnet synchronous motor without mechanical sensor," in conf. Rec. IEEE/IAS conf. Annu., pp. 55-60, 1995 .

[14] A. Consoli, G. Scarcella, G. Scelba, A. Testa, "Steady-state and transient operation of IPMSMs under maximum-torque-per-ampere control," IEEE Trans. Industry Applications, vol. 46, no. 1, pp. 121-129, Jan./Feb. 2010.

[15] F. F. M. EI-Sousy, M. Orabi, H. Godah, "Maximum power point tracking control scheme for grid connected variable speed wind driven selfexcited induction generator," Journal of Power Electronics, Vol. 6, no. 1, pp. 52-66, Jan. 2006. 


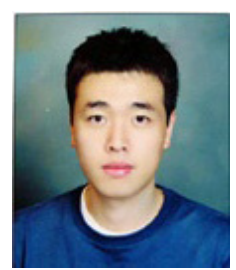

Yi-Kyu Kang was born in Kunsan, Korea, in 1984. He received his B.S. in Electrical Engineering from Chonbuk National University, Jeonju, Korea, in 2009. He is currently working toward his M.S. at Ajou University, Suwon, Korea. His current research interests include power conversion and electric machine drives.

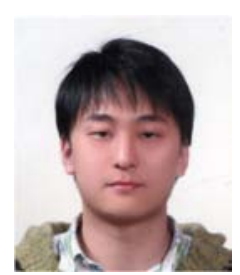

Hea-Gwang Jeong was born in Jeonju, Korea, in 1982. He received his B.S. in Electrical Engineering from Chonbuk National University, Jeonju, Korea, in 2008. He is currently working toward his M.S. at Ajou University. His current research interests include power conversion and electric machine drives.

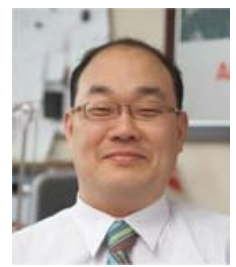

Kyo-Beum Lee was born in Seoul, Korea, in 1972 He received his B.S. and M.S. in Electrical and Electronic Engineering from the Ajou University, Korea, in 1997 and 1999, respectively. He received his Ph.D. in Electrical Engineering from Korea University, Korea in 2003. From 2003 to 2006, he was with the Institute of Energy Technology, Aalborg University, Aalborg, Denmark. From 2006 to 2007, he was with the Division of Electronics and Information Engineering, Chonbuk National University, Jeonju, Korea. In 2007 he joined the Division of Electrical and Computer Engineering, Ajou University, Suwon, Korea. He is an Associate Editor of the IEEE Transactions on Power Electronics and the Journal of Power Electronics. His current research interests include electric machine drives and wind power generation.

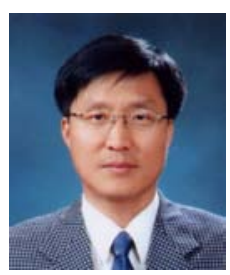

Dong-Choon Lee received his B.S., M.S., and Ph.D. in Electrical Engineering from Seoul National University, Seoul, Korea, in 1985, 1987, and 1993, respectively. He was a Research Engineer with Daewoo Heavy Industry from 1987 to 1988 . Since 1994, he has been a faculty member of the Dept. of Electrical Engineering, Yeungnam University, Gyeongbuk, Korea. Currently, he is a Full Professor and a Vice Dean of Academic Affairs, College of Engineering. Also, he is serving as a Publication Editor, Journal of Power Electronics, the Korean Institute of Power Electronics, Korea. As a Visiting Scholar, he joined the Power Quality Laboratory, Texas A\&M University, College Station in 1998, the Electrical Drive Center, University of Nottingham, U.K. in 2001, and the Wisconsin Electric Machines \& Power Electronic Consortium, University of Wisconsin, Madison in 2004. His current research interests include ac machine drives, control of power converters, wind power generation, and power quality.

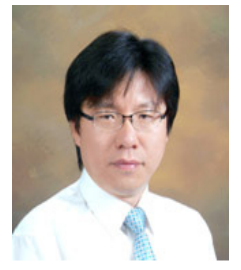

Jang-Mok Kim was born in Busan, Korea, in August 1961. He received his B.S. from Pusan National University in 1988, and his M.S. and Ph.D. from Seoul National University, Korea, in 1991 and 1996, respectively, in the department of Electrical Engineering. From 1997 to 2000, he was a Senior Research Engineer with the Korea Electrical Power Research Institute (KEPRI). Since 2001, he has been with the School of Electrical Engineering, Pusan National University (PNU), where he is currently a faculty member. In addition, he is a Research Member of the Research Institute of Computer Information and Communication at PNU. His present interests include the control of electric machines, electric vehicle propulsion, and power quality. 